\title{
Be Like a Tree
}

Heather Croke

hcroke7@hotmail.com

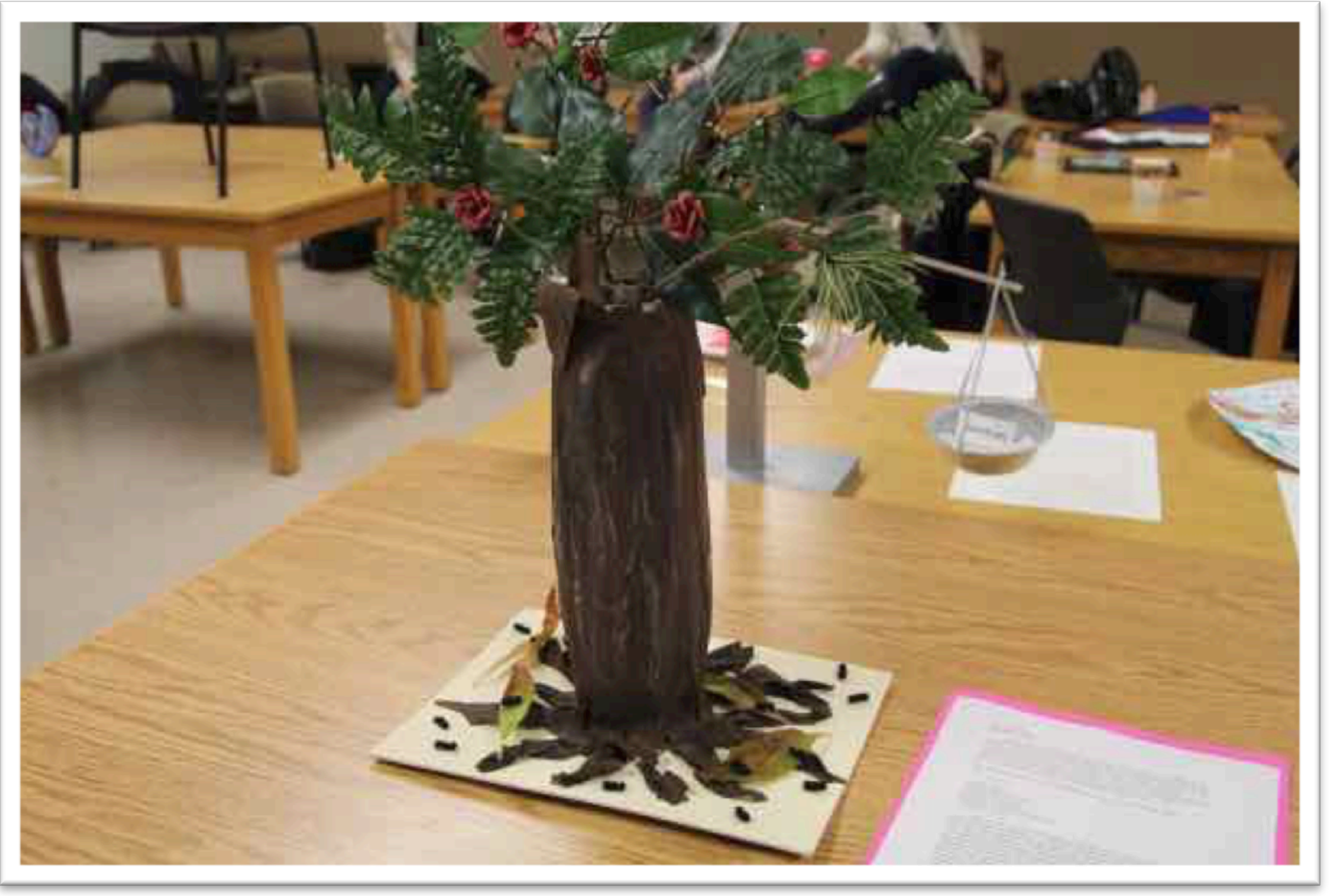

Inspired by a local community center, this visual representation speaks to the context of working with a population challenged by societal stigma. As social workers, we may find ourselves on the oppressed side of a power imbalance as stigma and the perception of greater society can overwhelm the work of smaller groups and communities. This power imbalance is certainly of concern as it can impede initiatives that could lead to positive change. Although discouraging, it is still important to persevere and create a space for social justice and empowerment.

\section{Equity, Diversity and Anti-Oppressive Practice and Social Work Practice Contexts}

My encounter with a significant power imbalance involved the impact of structural and societal stigma in relation to mental health. As mental health discourse is becoming more acknowledged, society's perception of the matter is crucial for promoting the need of community initiatives. This is consistent with the pursuit of social justice within social work practice contexts, in which social workers help facilitate community advocacy and resource awareness in hopes to reduce the barriers that societal stigma has presented. But when other communities and 
larger social structures are the culprits in perpetuating the stigma, it can be dispiriting to work from an empowerment or intrapersonal framework, because even if those experiencing the stigma change their perception about their oppression, the structural forces that give rise to the stigma still go unchanged (Cook, Purdie-Vaughns, Meyer, \& Busch, 2013, pp. 102-103).

Witnessing a community's perseverance through this oppression is a source of empowerment for my social work career, but it is difficult not to experience a sense of powerlessness knowing that societal stigma can alienate a group of people so easily. As stigma can also act as an important social determinant of health, it can dramatically impact the relationship with other interacting elements in an environment, such as healthcare services and support availability, community partnerships, mental health education, social/coping skills, housing stability, and employment. A social worker can face a multitude of challenges while working within this context due to the negative relationships that are interconnected with stigma. In this context, practicing anti-oppressively would most certainly consist of highlighting the community's strengths and diversity, and valuing the intersectionality of their experiences. Antioppressive practice challenges us to question societal norms around perpetuated stigma and emphasizes the need to build community relationships for high quality social justice action (Baines, 2011, p. 23). Using the concept of a tree to convey these themes demonstrates how so many elements impact the growth of a tree, while also highlighting its strength against negative outside forces.

The main structure of my representation, a tree, was motivated by the quote from Joanne Raptis 'Be like a tree.' Considering the aforementioned themes, using the concept of a tree captures multiple elements of my experience. It represents the specific community context in which my social work practicum was involved. It conveys the concept of structure and how damage to the tree is caused by larger outside forces, of which can impact growth and development. As presented in my visual piece, the roots are dark and rugged to speak for the community's historical endurance of hardship and societal stigma. The different shades of light and dark on the trunk of the tree show both the adversity and prosperity of the community as society developed. The structures of the branches are deliberately different to represent the various interconnections of social work anti-oppressive practice and resources used to engage in advocacy. Speaking to the highs and lows the community dealt with during their mental health initiatives, the fallen leaves present the concept of oppression and a sense of defeat, while the thriving flowers represent the positive community outcomes and relationships built through perseverance. As this assignment allowed for greater self-reflection, critical thinking, and appreciation of my practicum encounters, the leaves and flowers subsequently capture my feelings of sympathy, discouragement, acceptance, optimism, and empowerment that I experienced while learning about their journey and my position as an aspiring social worker. The ants were a last minute touch, but definitely a valuable concept. The ants represent restless, resilient, and diverse individuals working together for the benefit of the whole. Not only is this applicable to how the community has worked together to fight against longstanding stigma, but also to how various community partners have engaged with the community to challenge mental health stigma. 


\section{References}

Baines, D. (2011). Doing anti-oppressive practice: Social justice social work (2 ${ }^{\text {nd }}$ ed.). Halifax, NS: Fernwood Publications.

Cook, J. E., Purdie-Vaughns, V., Meyer, I. H., \& Busch, J. T. A. (2013). Intervening within and across levels: A multilevel approach to stigma and public health. Social Science \& Medicine, 103(2014), 101-109. 